\title{
PERICARDIAL VALVE FOR PULMONARY VALVE REGURGITATION
}

\section{Antonio F. Corno ${ }^{1}$, Suhair O. Shebani2, Gregory J. Skinner², Aidan P. Bolger², Imran Saeed2, Ikenna Omeje2 , Branko Mimic ${ }^{2}$}

1 Cardiovascular Research Center, University of Leicester, Leicester, U.K.

2 East Midlands Congenital Heart Center, Glenfield Hospital, Leicester, U.K.

\section{OBJECTIVE}

To evaluate the "off label" surgical implantation of an aortic pericardial Pulmonary Valve (PV) for the treatment of PV regurgitation.

PV IMPLANTATION for REGURGITATION after repair of CONGENITAL HEART DEFECTS

ideal characteristics

-suitable for any size and morphology of the Right Ventricular Outflow Tract

-easy and reproducible surgical technique, with beating heart

- large size valve, for future percutaneous valve-in-valve implantation

-associated with Right Ventricular surgical

TRIFECTA - St. Jude Medical - Abbott
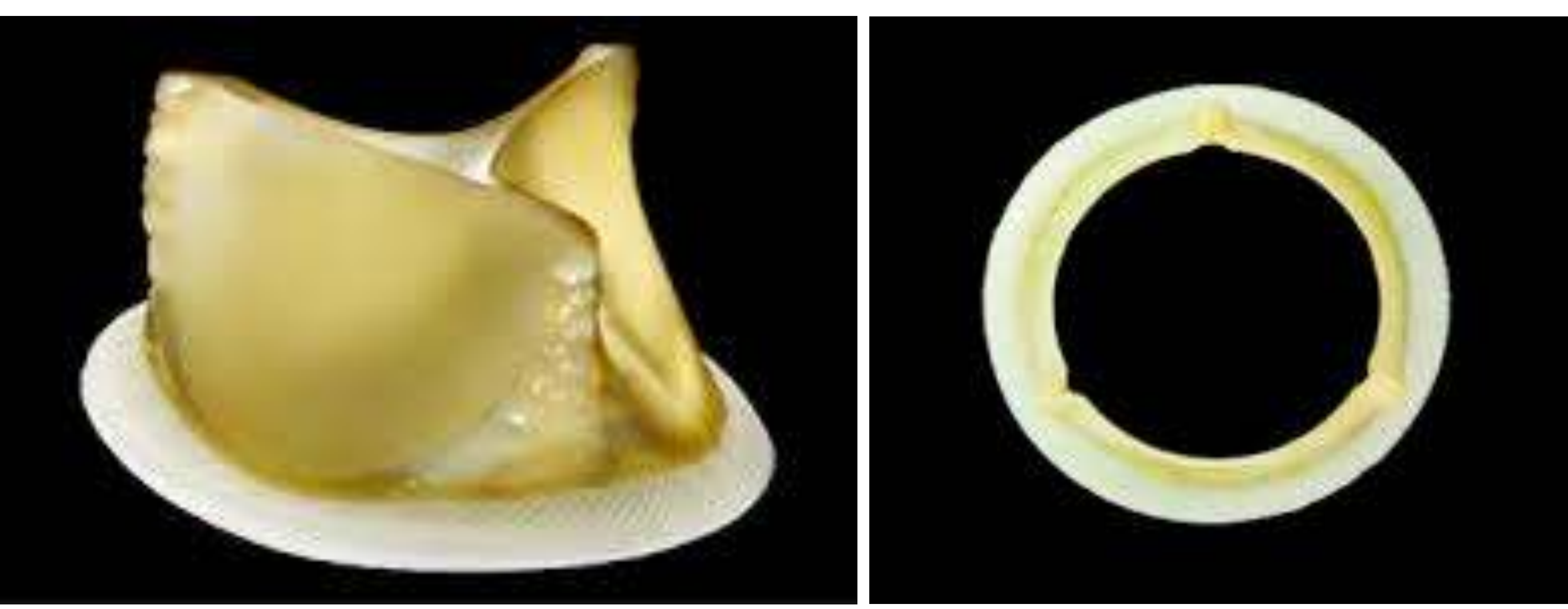

-tri-leaflet stented pericardial valve, designed for the aortic position

-polyester-covered titanium stent, entirely covered with porcine pericardial tissues

valve leaflets fabricated from bovine pericardium

The size of implanted PV was $19 \mathrm{~mm}$ in 3

patients, $21 \mathrm{~mm}$ in $7,23 \mathrm{~mm}$ in 43, $25 \mathrm{~mm}$ in 37 . $27 \mathrm{~mm}$ in 26, and $29 \mathrm{~mm}$ in 2

The Z-score of implanted PV was $0.16 \pm 0.80$ (range -1.6 to +2.5),

Indexed Effective Orifice Area of implanted PV was $1.3 \pm 0.3$ (range 0.8 to 2.5 ) versus normal PV $1.5 \pm 0.2$ (range 1.2 to 2.1 ) (N.S.).

Mean time to tracheal extubation was $5 \pm 4$ hours (range 0 to 26 hours), mean duration of ICU stay $19 \pm 10$ hours (range 12 to 64 hours), hospital stay $5 \pm 2$ days (range 3 to 19 days).

In a mean follow-up of $29 \pm 19$ months (range 3 to 67 months) there were no early or late deaths, one valve replacement after 3.5 years because of valve dysfunction.

Last echocardiography investigation showed absent PV regurgitation in $77 \%(91 / 118)$ patients, trivial/ mild in $22 \%(26 / 118)$, and moderate in $1 \%$ $(1 / 118)$.

Mean max peak velocity through the RVOT was $1.8 \pm 0.4 \mathrm{~m} / \mathrm{sec}$ (range 1.2 to $2.6 \mathrm{~m} / \mathrm{sec}$ ). Mean RVEF $55 \pm 4 \%$ (range 49 to $61 \%$ ) was significantly better than pre-operative $(P<0.05)$, mean indexed RV End-Diastolic Volume at MRI and/or KBR3DV evaluation was $96 \pm 20$ (range 63
METHODS

From July 2012 to December 2017118 patients, mean age $23 \pm 3$ years (range 4 to 70 years),

mean body weight $62 \pm 23 \mathrm{~kg}$ (range 15 to $112 \mathrm{~kg}$ ), underwent surgical PV implantation.

Previous surgery was:

-repair of tetralogy Fallot (in 105/118 =89\%)

- PValvotomy (in 10/118 = 8\%)

-RVOTO relief (in $2 / 118=2 \%$ )

-arterial switch (in $1 / 118=1 \%$ )

Previous surgery occurred at a mean age of $3.2 \pm 6.2$ years (range 1 month to 49 years), with a mean interval of $20 \pm 11$ years (range 2 to 56 years).

On pre-operative echocardiography and MRI the degree of PV regurgitation was severe in 114/118 = $97 \%$ of patients, and moderate in $4 / 118=3 \%$.

Recurrent RVOT obstruction was associated in 10/118 $=8 \%$ of patients.

Cardiac MRI and Knowledge-Based-Reconstruction 3DVolumetry (KBR3DV) showed:

-mean PV regurgitation $42 \pm 8 \%$ (range 22 to $58 \%$ )

-mean RVEF $46 \pm 8 \%$ (range 33 to $61 \%$ )

-mean indexed RV End Diastolic Volume $174 \pm 34$

(range 130 to 282 ) $\mathrm{mL} / \mathrm{m}^{2} B S A$

At the effort test the mean peak 02 uptake was $24 \pm$ $7 \mathrm{ml} / \mathrm{kg} / \mathrm{min}$ (range 18 to $45 \mathrm{ml} / \mathrm{kg} / \mathrm{min}$ ), with

predicted max 02 uptake $64 \pm 16 \%$ (range 26 to $97 \%$ )

NYHA class was:

-I in $14 / 118=12 \%$

CARDIAC MRI FLOW IMAGING
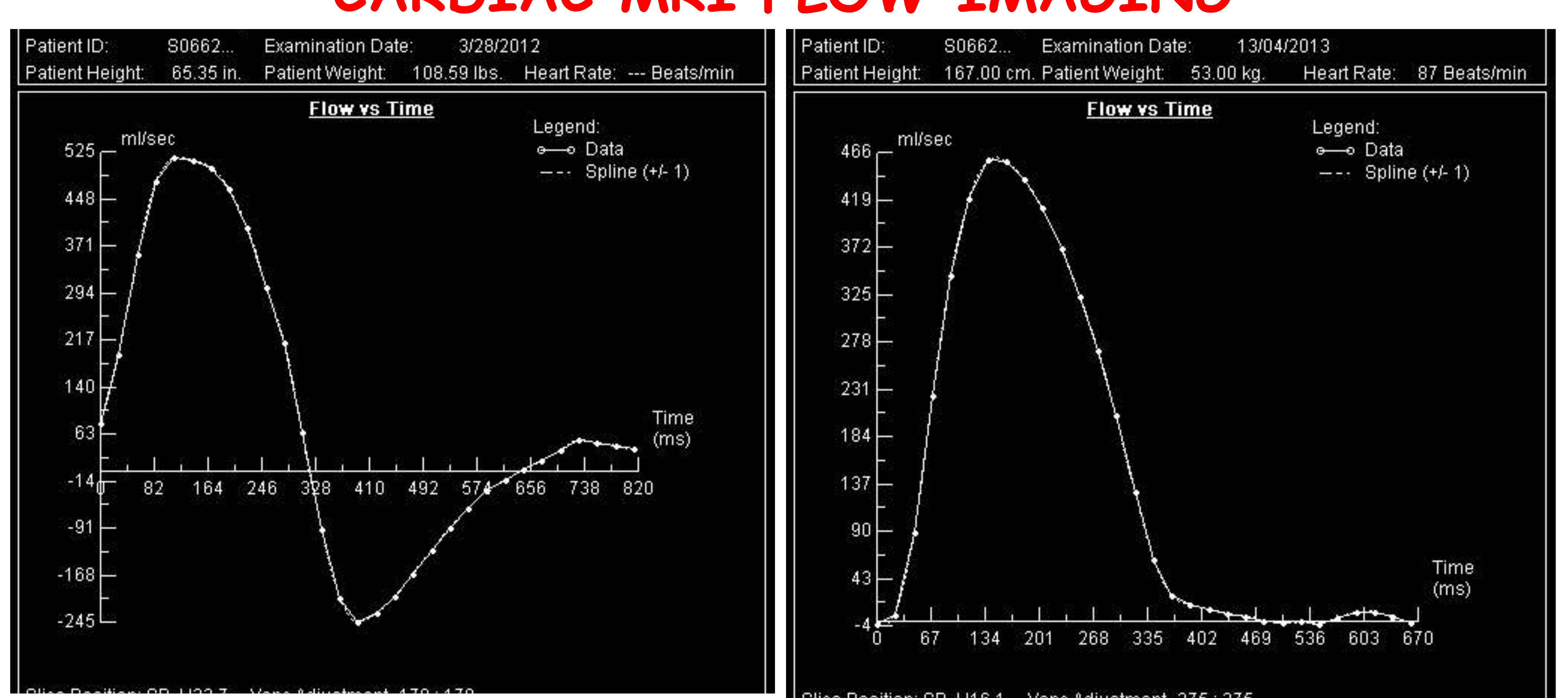

before PV implantation

after PV implantation

- the "off label" surgical implantation of an aortic pericardial Pulmonary Valve for severe PV

Regurgitation is safe and reproducible with improved RV Ejection Fraction, reduced RV dimensions and maintained Pulmonary Valve function on medium term - large size Pulmonary Valve facilitates later percutaneous valve-in-valve implantation

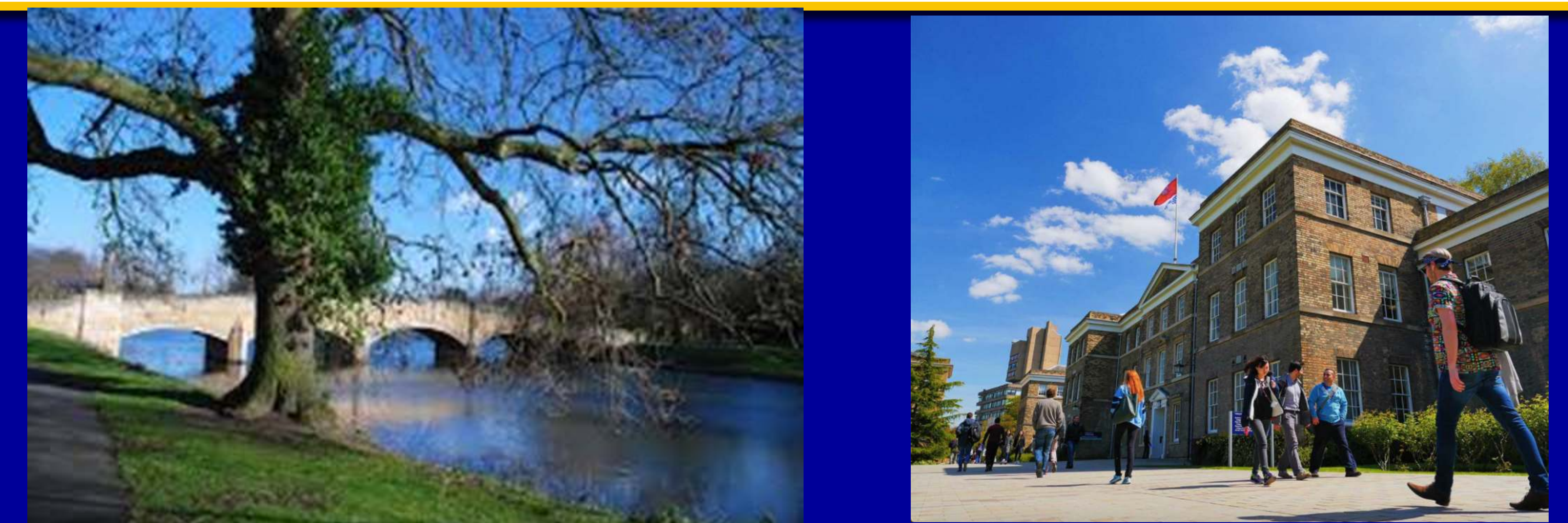

